This PDF is a selection from a published volume from the National Bureau of Economic Research

Volume Title: Social Security Programs and Retirement around the World: The Relationship to Youth Employment

Volume Author/Editor: Jonathan Gruber and David A. Wise, editors

Volume Publisher: University of Chicago Press

Volume ISBN: 978-0-226-30948-4; 0-226-30948-7

Volume URL: http://www.nber.org/books/grub08-1

Conference Date:

Publication Date: February 2010

Chapter Title: Social Security Incentives, Exit from the Workforce and Entry of the Young

Chapter Author: Michele Boldrin, Pilar García-Gómez, Sergi Jiménez-Martín

Chapter URL: http://www.nber.org/chapters/c8259

Chapter pages in book: (261 - 294) 


\title{
Social Security Incentives, Exit from the Workforce, and Entry of the Young
}

\author{
Michele Boldrin, Pilar García-Gómez, and \\ Sergi Jiménez-Martín
}

\subsection{Introduction}

Beginning in the late 1970s, Spain has witnessed dramatic social, economic, and demographic changes. Life expectancy has increased substantially, and fertility rates have dropped to some of the lowest levels in the European Union (EU). The Spanish public system of social insurance, of which the public pension system (Seguridad Social) is the main component, underwent a major reform in the middle 1980s and is now substantially more comprehensive and generous than it used to be. Finally, Spanish per capita income has grown continuously since the middle 1980 s, on average at about a percentage point faster than the rest of the EU, and the growth has been comparatively higher since the late 1990s. During the same period, a large share of the older workers population have been dismissed and lead to retire earlier, while the population unemployment rate soared first and then, since 1996, declined steadily to reach average European levels in the last three years.

Quite often during the last three decades, policies that favor early retirement are supported and promoted with the justification that they may induce a reduction in youth unemployment rates. The basic idea is that because jobs are a scarce resource available in a fixed number, retiring an older worker would "free" the same job for a younger, most likely unemployed, one.

Michele Boldrin is the Joseph Gibson Hoyt Distinguished Professor of Economics in Arts and Sciences and Department Chair at Washington University in St. Louis, and a research fellow of CEPR in London and of FEDEA in Madrid. Pilar García-Gómez is an assistant professor at the Erasmus School of Economics at Erasmus University Rotterdam. Sergi JiménezMartín is associate professor of economics at Universitat Pompeu Fabra and Director of the LaCaixa-FEDEA chair on Health Economics.

We are grateful to MEC projects SEJ2005-08783-C04-01 and EC02008-06395-C05-01 for financial support. 
We have found a number of references to this issue in the press during the early eighties. Just as an example, we mention the preamble of the national employment agreement of 1981 (Acuerdo nacional sobre empleo; El País, July 6, 1981) describing a special retirement scheme (Sistema especial de jubilaciones): ${ }^{1}$

Las partes firmantes del acuerdo han examinado los posibles efectos sobre el empleo del establecimiento de un sistema que permita la jubilación con el 100\% de los derechos pasivos de los trabajadores al cumplir 64 años de edad y la simultánea contratación por parte de las empresas de trabajadores jóvenes o perceptores del Seguro de Desempleo en número igual al de las jubilaciones anticipadas que se pacten con contratos de igual naturaleza que los que se sustituyen. El Gobierno elaborará, en el plazo de 2 meses, una norma estableciendo la regulación de un sistema que, por la vía de los convenios colectivos o del acuerdo entre empresas y trabajadores, permita las sustituciones a que se refiere el párrafo anterior.

[The signed parties of the agreement have examined the possible effects on employment of a system that allows retirement with 100 percent of the liability rights of the workers when they become sixty-four years old and the simultaneous hiring from the firm of young workers or receivers of unemployment benefits with contracts of the same nature as the ones to be substituted in equal number as the early retirees agreed. The Government will devise, in a two months period, a rule establishing the regulation of a system that, via collective agreements or agreement between employers and employees, allows the substitutions referred above.]

In fact, the 1985 pension system reform, which gave shape to the system currently in place, ${ }^{2}$ introduced several specific programs to favor the substitution of older by younger workers. Especially relevant are the Jubilación Especial (special retirement scheme) at age sixty-four and the Jubilación Parcial (partial retirement). The first one has been always very marginal, with an incidence varying from 1 to 4 percent of the total number of retirees. The second has not been used until very recent years, after the 2002 reform. In fact, the incidence of this scheme was negligible until 2002. Since then, it has increased very rapidly (4.24 percent in 2002 and 13.27 percent in 2007). See table 9A.1 for recent information about the distribution of the retirement pensions awarded in recent years. Unfortunately, a large share of this time period is out of our sample and cannot be taken into consideration.

1. Other mentions of the issue can be found in International Labor Organization (ILO) documents (Medidas de la OIT para luchar contra el desempleo. El Pais, 17/08/1982. http:// www.elpais.com/articulo/economia/PAISES_INDUSTRIALIZADOS/ORGANIZA CION_INTERNACIONAL_DEL_TRABAJO_/OIT/Medidas/OIT/luchar/paro/elpepieco/ 19820817elpepieco_10/Tes; also in an article on El País (Artículo de opinión en El País 26/11/1983 de Daniel Gil. http://www.elpais.com/articulo/opinion/edad/jubilaciones/elpepiopi/ 19831126elpepiopi_10/Tes. More recently, in 2002, we have found another reference to the issue in Trade unions news: http://www.ugtrioja.org/web/actualidad/cp/cp219.htm.

2. There have been three reforms after 1985: 1997, 2002, and 2007. However, the shape of the system has remained unaltered since the 1985 reform. 
Our goal is to understand the relationship between the employment (or exit from the labor force) of the old and the employment/unemployment of the young. To do this, we first estimate the statistical impact of the labor force participation (LFP) of the old on the employment/unemployment of the young, and also of the middle-aged individuals. However, changes in the LFP of the old may be due to factors other than changes in pension incentives, which may also be correlated with the labor conditions of the young, thus giving biased estimates. Therefore, one would like to estimate the direct effect of retirement policies.

More precisely, we would like to estimate at the aggregate level the direct relationship between the incentive for the old to leave the labor force and the employment of the young. In order to do so, we need a simple aggregate indicator of the incentive to retire. However, to obtain such an index may be complicated, especially recognizing the need to account for some key aspects of the inducement to retire: the eligibility age, the benefit level given eligibility, and the change in the benefit if the receipt of benefits is delayed (the option value/peak value [OV/PV] idea, essentially the actuarial adjustment if retirement is delayed); and the necessity to aggregate them for all the individuals "at risk" in a given year.

Methodologically, our approach is very simple: we collect time series information of the main indicators of the Spanish labor market for the key groups of the population; in parallel, we construct synthetic incentive measures for the at risk population in a given year. To do this, we combine data from the Spanish Labor Force Survey and the Muestra Continua de Vidas Laborales (MCVL2006).

Previous works on the relationship between employment of the young and exit of older workers in Spain (Jiménez-Martín 1999) and Europe (Boldrin et al. 1999) have found no systematic evidence of any significant correlation. Jiménez-Martín (1999) analyzes the relationship between young's entry and older's exit from the labor market in Spain using data from the panel data version of the Spanish Labor Force Survey in the 1987 to 1997 period. He analyzes the individual decision to enter the labor market (transitions into the "market") while controlling for individual and household characteristics as well as local market indicators. Among the latter, he highlights the fraction/amount of exit from the labor market on the part of older individuals, especially those aged fifty-five to sixty-four. He finds little evidence of any relationship between entry of the young and exit of older individuals.

Boldrin et al. (1999) collected various labor market observations for a sample of 260 Nomenclature of Territorial Units for Statistics (NUTS) II and NUTS III European regions over the years 1986, 1991, and 1996. ${ }^{3}$ They expect that, if any effect is visible, it should be detectable at this level of

3. They represent relatively small areas, which happen to be the territorial units at which the European Commission targets its employment policies and for which national governments tend to devise the early retirement plans we mentioned earlier. 
geographical disaggregation. Figures 2 and 3 in Boldrin et al. (1999) plot, separately for men and women, the relationship between the exit rates from the labor force of people born between 1931 and 1940, and the changes in the unemployment rates over 1991 to 1996 of people aged between twentyone and thirty. Under the substitution hypothesis, we should expect a negative relationship. Neither for men nor for women, the estimated regression lines turn out to be significantly negatively sloped. For alternative specifications, controlling for cohort effects or using different lags, the results hardly change. Thus, they conclude that early retirement of older workers does not come together with a reduction of unemployment among younger people.

The rest of this document goes as follows. In section 9.2, we document the main macroeconomic facts of the last decades. In section 9.3, we describe the social security background. Data and sources are commented in section 9.4. In section 9.5, we discuss the trends of the labor force during the period of study. In section 9.6 we present the methodology and the construction of the inducement-to-retire measure and, in section 9.7, the empirical framework used to test the relevant hypothesis. The empirical results are described in section 9.8. Finally, section 9.9 offers some concluding remarks.

\subsection{The Facts}

\subsubsection{Macroeconomic Context}

Table 9.1 summarizes the Spanish macroeconomic evolution, in relation to the EU's average, since 1975. The basic facts for Spain are as follows. ${ }^{4}$ In the period immediately after the oil shock, 1975 to 1985 , which coincides with the death of Francisco Franco and the beginning of the democratic transition, both the gross domestic product (GDP) growth rate and the level of employment were well below the European average. This period corresponds to a dramatic "structural transition" in which a few million jobs were eliminated and the unemployment rate skyrocketed to levels substantially above 20 percent. This was only partially a consequence of the two oil shocks; the collapse of the Franco regime led to a spontaneous and unplanned "opening" of the economy, which preceded and anticipated the entrance into the EU by almost a decade. As a consequence of this broad restructuring process, productivity growth in Spain was by far more intense than the European average until the second half of the 1980s. In the period since 1985, the opposite happened: productivity growth in Spain is slightly but persistently below the EU average, while GDP and employment grow, on average, faster than in the rest of Europe. The last thirteen years, in particular, have seen a spectacular increase in Spanish employment (more

4. Source material is from Eurostat. 


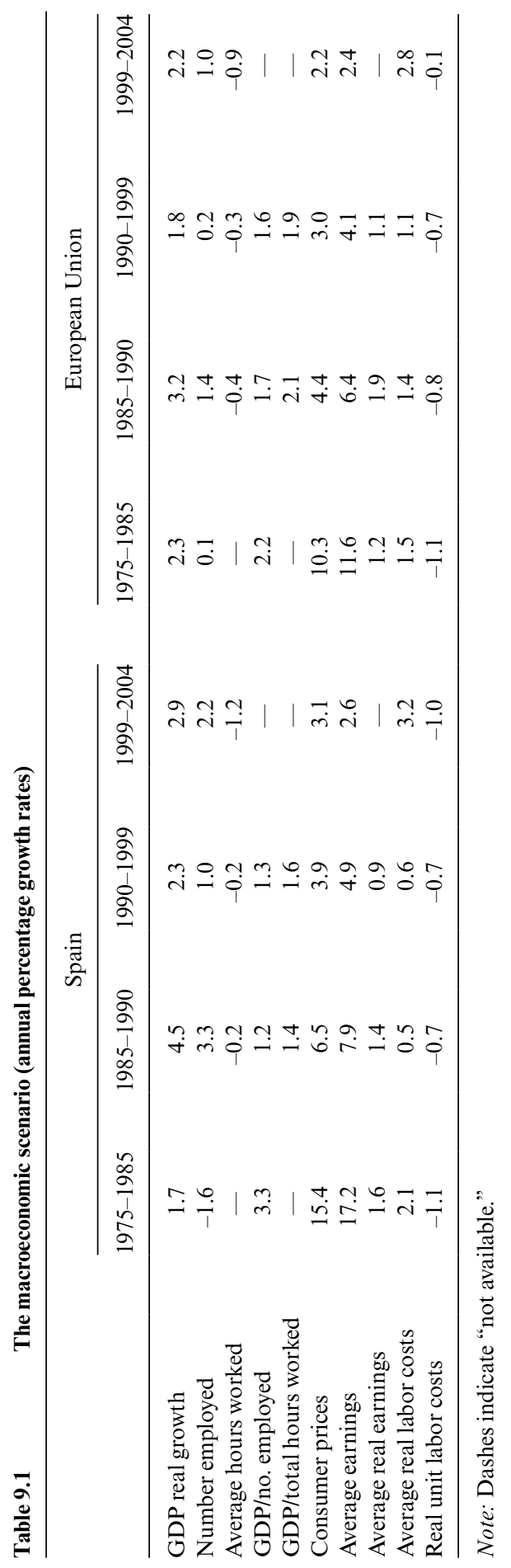


than eight million additional jobs out of a total employment, in 1995, of about twelve million), which has, nevertheless, come together with a very slow rate of growth in labor productivity. Inflation, on the other hand, has been slightly above the European average during the whole period, although the differential has been reduced in recent years, following the implementation first of the Maastricht pact and then of the Euro. Finally, real unit labor costs have been decreasing at about the EU average during the whole period.

What are the implications of these macroeconomic facts for our purposes? Basically, that the relative economic position of Spain, and of the average Spaniard, has improved substantially, vis-á-vis that of the average European, during the last thirty years. The natural question to ask, therefore, is: did this improvement in the economic well being of the average Spaniard translates also into an improvement of the economic conditions of the elderly? Figure 9.1 reports the ratio of pension expenditure to GDP since 1965. It is apparent that this ratio has grown substantially for about thirty years and has flattened out and then slightly decreased during the last ten years or so.

\subsubsection{Labor Market Reforms since the 1970s}

There have been substantial changes in employment protection legislation over the last three decades. The following chronology describes the major ones:

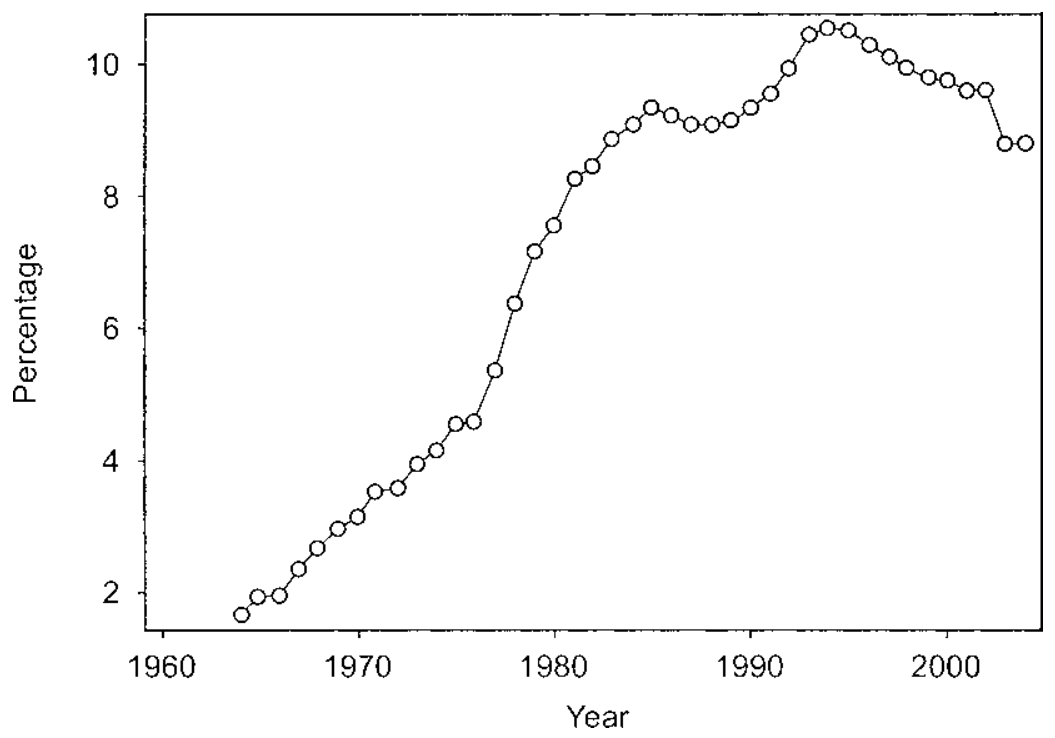

Fig. 9.1 Pension expenditure to GDP ratio 
- 1978: Following the transition to democracy, Spain introduced labor legislation restricting dismissals and adding high dismissal costs. ${ }^{5}$

- 1980: The parliament passed the Workers' Statute including the Strike and Collective Bargaining regulation. At the same time, early retirement provisions and the notion of "disability due to economic reasons" are introduced.

- 1984: First reform of the labor market with the objective of reducing dismissal cost. Temporary contracts are introduced that became very popular since (as shown in table 9.2). As a result of the 1984 reform, the proportion of employees under temporary contracts increased from 10 percent during the 1980s to over 30 percent in the early 1990s. The temporary contracts generated a dual labor market: unstable low-paying jobs and stable high-paying jobs under the old regulation. It did not reduce unemployment until the recovery of 1994 (Kugler, Jimeno, and Hernanz 2002). Not surprisingly, reducing firing costs has been one of the recurrent recommendations of national and international organizations, although actual reforms had only a limited scope (Organization for Economics Cooperation and Development [OECD] (2005).

- 1994: Second major reform of the labor market, with the objective of introducing limitations to the use of temporary contracts.

- 1997: Third important reform of the labor market (actualized in 2001). The purpose of this reform was to further limiting the incentive to use temporary contracts by reducing dismissal cost of certain groups of workers. The most noted aspect of the reform was the introduction of a new permanent contract, with reduced severance payments. This contract was targeted to two groups: the population most exposed to unemployment (i.e., the youth, the long-term unemployed, and women and men above age forty-five) and workers on a temporary contract who

5. This legislation established that firms could dismiss workers for "personal reasons," in which case the firm had to prove the worker's incompetence or absenteeism, and "economic reasons," in which case the firm had to prove its need to reduce employment due to technological, organizational, or productive causes. Dismissals justified by "economic reasons" required advance notice. Workers dismissed for "personal reasons" could appeal to labor courts. The severance payment awarded depended on whether judges ruled the dismissal as "fair" or "unfair." A dismissal was ruled as "fair" if the employer was able to prove the worker's incompetence or absenteeism and "unfair" otherwise. In case of fair dismissals, firms had to pay twenty days out of the salary per year of seniority, with a maximum of twelve months. In the case of unfair dismissals, firms had to pay forty-five days per year of seniority out of the salary, with a maximum of forty-two months. Severance payments for "economic reasons" were the same as for fair dismissals under "personal reasons." In practice, this legislation turned out to be very stringent because judges ruled dismissals as unfair in the majority of cases. Moreover, approval for dismissals under "economic reasons" was often granted only when there was an agreement between employers and workers, which was achieved in most cases by raising severance payments above the legally established amounts. The Spanish government introduced the first reform designed to reduce dismissal costs in 1984. Because an across-the-board reduction of dismissal costs was politically impossible, the reform liberalized the use of temporary contracts (from Kugler, Jimeno and Hernanz 2002). 


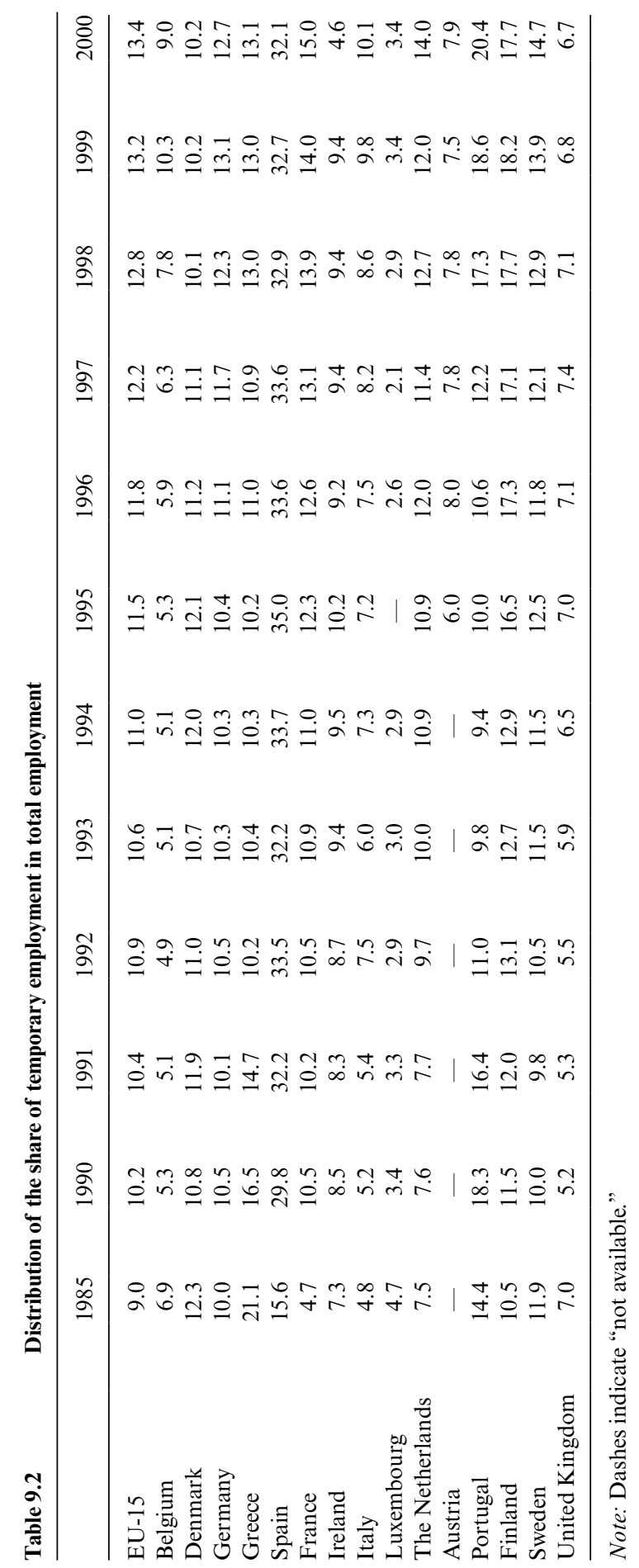


converted to an indefinite one during the one-year period following the approval of the new legislation.

- 2006: Fourth important labor market reform. Previous reforms had failed to reduce the fraction of temporary contracts; a new attempt was made by introducing strong restrictions on the extension of contracts or replacement of temporary workers.

\subsubsection{Background on the Spanish Social Security System}

Mandatory insurance for job related accidents was introduced in 1900 , through a bill that also authorized the creation of some funds, for public employees only, paying disability and retirement pensions. In 1919, mandatory retirement insurance (Retiro Obrero Obligatorio) was introduced for private-sector employees aged sixteen to sixty-five whose total annual salary was below a certain threshold. In 1926, a universal pension system for public employees (Régimen de Clases Pasivas, or RCP) was established, which still exists under the same name. By the late 1930s, most Spanish employees were covered, in one form or another, by some minimal, government mandatory retirement insurance program.

With the end of the Republic and the advent of Franco's regime, a number of changes were implemented. In 1939, Workers' Retirement (Retiro Obrero) was replaced by Old Age Insurance (Seguro de Vejez). While the former was based upon a capitalization system, the latter was from the beginning a completely unfunded pay-as-you-go scheme. By 1950, the system had acquired its basic organization in two pillars, which remained essentially unchanged until the mid 1970s. Public servants were all covered by the RCP, while private-sector employees with annual earnings below a certain ceiling were covered by the Old Age Insurance. The 1963 reform created a very large number of special funds (Régimenes Especiales) next to the general scheme (Régimen General), generating a jungle of special treatments that is still being dismantled.

In 1977, a reform bill made a first attempt at harmonizing the many existing funds, by reducing the differences in the treatment they offered and by putting (in 1979) the administration of the whole system under the newly created National Social Security Institute (Instituto Nacional de la Seguridad Social, or INSS). Overall, this process increased the percentage of workers covered by the public social security system.

The key rules before the 1985 reform (see Barrada [1999] or Boldrin, Jiménez-Martín, and Peracchi [1999] for a complete description) were the following:

1. The Normal Retirement Age is set at sixty-five and the Early Retirement Age, for those that started contributing before 1967, at sixty.

2. Eligibility: ten years of contributions, of which two years should be in the last seven years preceding the date of retirement. 
3. Amount of pension: 50 percent of the "benefit base" with ten years of contributions, plus 2 percent for each additional year of contributions, up to 100 percent with thirty-five years.

The reform process, which came to shape the current regime, introduced a few important changes: eligibility criteria for disability pensions were tightened; the minimum number of years of contributions required to obtain an old-age pension was increased from eight to fifteen; and the number of years entering the computation of the benefit base was increased from two to eight. On June 26, 1997, many of the parameters used for the computation of benefit bases and pensions were modified. The number of contributory years over which the benefit base is computed was increased from eight to fifteen (by year 2001). The formula for the computation of the replacement rate $\alpha$ (see the following) was also made less generous, whereas the 8 percent per-year penalty applied to early retirees between the ages of sixty and sixty-five was reduced to 7 percent for those individuals with forty or more contributory years at the time of retirement.

Currently, the Spanish social security offers two pathways to regular retirement: ${ }^{6}$ early retirement and normal retirement. Early retirement is possible starting at age sixty, while the normal retirement age is sixty-five, although some professional groups have lower normal retirement ages (miners, military personnel, policemen, and fishermen are the main ones). Collective wage settlements often impose mandatory retirement at age sixty-five, facilitate retirement at sixty-four with full benefits, or encourage retirement between sixty and sixty-three through lump-sum payments.

Public pensions are provided by the following programs:

- The "General Social Security Scheme" (Régimen General de la Seguridad Social, or RGSS) and the "Special Social Security Schemes for Self-Employed" (Régimen Especial de Trabajadores Autónomos, or RETA). They cover, respectively, the private-sector employees and the self-employed workers and professionals. The RGSS covers also the members of cooperative firms, the employees of most public administrations other than the central governments, and all unemployed individuals complying with the minimum number of contributory years when reaching sixty-five.

- The scheme for government employees (Régimen de Clases Pasivas, or RCP) includes public servants employed by the central government and its local branches.

In what follows, we provide a brief summary of key regulatory changes in the Spanish social security system.

6. That is to say, in the absence of disability or long-term unemployment in late age. 
- 1973: Social Security Act: Introduction of the tax base (not linked to wages) but to categories.

- 1974: Social Security Bill: Effectively linked the tax base to wages. Loosened significantly the eligibility criteria. Common replacement rates.

- 1977: Harmonization Process: Caused a significant increase of coverage.

- 1985: First major pension system reform. It included restrictions in the access to invalidity very frequent in the period 1980 to 1985 . It introduced several Early Retirement programs: Jubilación Parcial, Jubilación Flexible, and Jubilación Especial a los 64. Consistent increase of the Minimum Pension to the Minimum Wage since then.

- 1997: Second Pension Reform. Following the Toledo Pact (1995). Very little effect on either incentives or pension expenditure.

- 2002: Third Pension Reform. Early Retirement up to sixty-one (but not affecting current workers). Very little effect on either incentives or pension expenditure in the short run. The incentives to use the partial retirement program were increased, and this program has been increasingly used as an exit route.

- 2007: Fourth Pension Reform (Ley 40/2007). Marginal changes on eligibility for retirement options. Important changes on eligibility (change to fifteen years or 5.475 days of effective contributions), conditions for allowing for partial retirement, and formula for disability insurance (DI) benefits.

See the appendix for a detailed description of the system rules from 1985 onward.

\subsection{Description of Data and Sources}

We start by providing an index of the data sets that are currently available. One important limitation should be noticed: there is no single data set covering the whole period 1975 to 2005. Most time series, therefore, will be constructed by splining data from different sources, creating obvious problems of consistency, which, while less dramatic than one might expect, are nevertheless substantial.

\subsubsection{Data Sources}

\section{Employment}

Data about employment and labor force participation come from the Encuesta de Población Activa (EPA). The EPA is a rotating quarterly survey carried out by the Spanish National Statistical Institute (Instituto Nacional de Estadistica, INE). The planned sample size consists of about 64,000 
households with approximately 150,000 adult individuals. Although the survey has been conducted since 1964, publicly released cross-sectional files are available only from 1977. The 1977 questionnaire was modified in 1987 (when a set of retrospective questions was introduced) and again in the first quarter of 1992. In both cases, the lengthening of the questionnaire led to increased nonresponse rates. Further modifications have been introduced in 1999 and 2004.

The EPA provides fairly detailed information on labor force status, education, and family background variables but, as with most European-style labor force surveys, no information on earnings and other sources of income. The reference period for most questions is the week before the interview.

\section{Wage Profiles and Incentive Variables}

Both wage profiles and monetary incentive variables are constructed using data from: (a) Historiales Laborales de la Seguridad Social, 1998 (old version): a sample of about 250,000 of working careers (Social Security numbers) taken at the end of 1997 (See Boldrin, Jiménez-Martín, and Peracchi 2001, 2004) for a description); complete working histories up to 1998 and monthly covered wages for employees in the 1986 to 1995 , which allows us to construct year of birth $\times$ gender $\times$ region wage profiles and, thus, incentives. (b) Muestra Continua de Vidas Laborales (MCVL2006): a sample of about $1,000,000$ of working careers (Social Security numbers) taken at the end of 2005; complete working histories up to 2006 and monthly covered wages for employees in the 1980 to 2005 period, which allows us to construct year of birth $\times$ gender $\times$ region wage profiles and, thus, incentives.

\subsubsection{Labor Force Trends from 1977 to 2005}

In this section, we present some descriptive and graphical evidence on labor force trends by gender for the groups under study. We also show a first glimpse of the relationship between the labor status of the different groups and the different labor and social security reforms. Figure 9.2 shows the evolution of the labor force participation, the employment rate, and the unemployment rate for the population aged sixteen to sixty-nine by gender. It can be seen that there has been an important increase in the female labor force participation since the mid-1980s, while the employment and unemployment rate of both males and females have been moved in parallel, decreasing (increasing) the employment (unemployment) rate during the mid-1980s, and an increase (decrease) in employment (unemployment) rates after the mid-1990s.

Figures 9.3 and 9.4 present some data to set the stage. They show how the employment and unemployment rate of the youth and the prime age individuals relate to the labor force participation of the older group (fiftyfive to sixty-nine) and whether the labor market or social security reforms can play any role. The employment and unemployment figures of young 


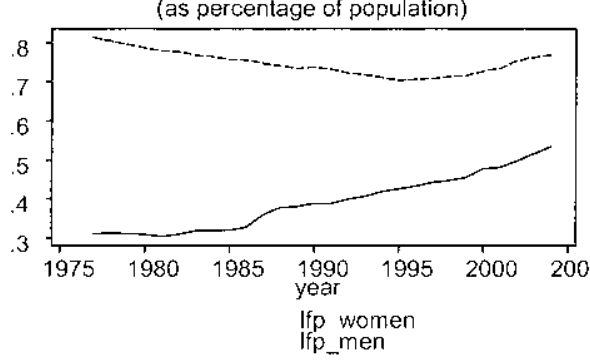

(as percentage of LFP)
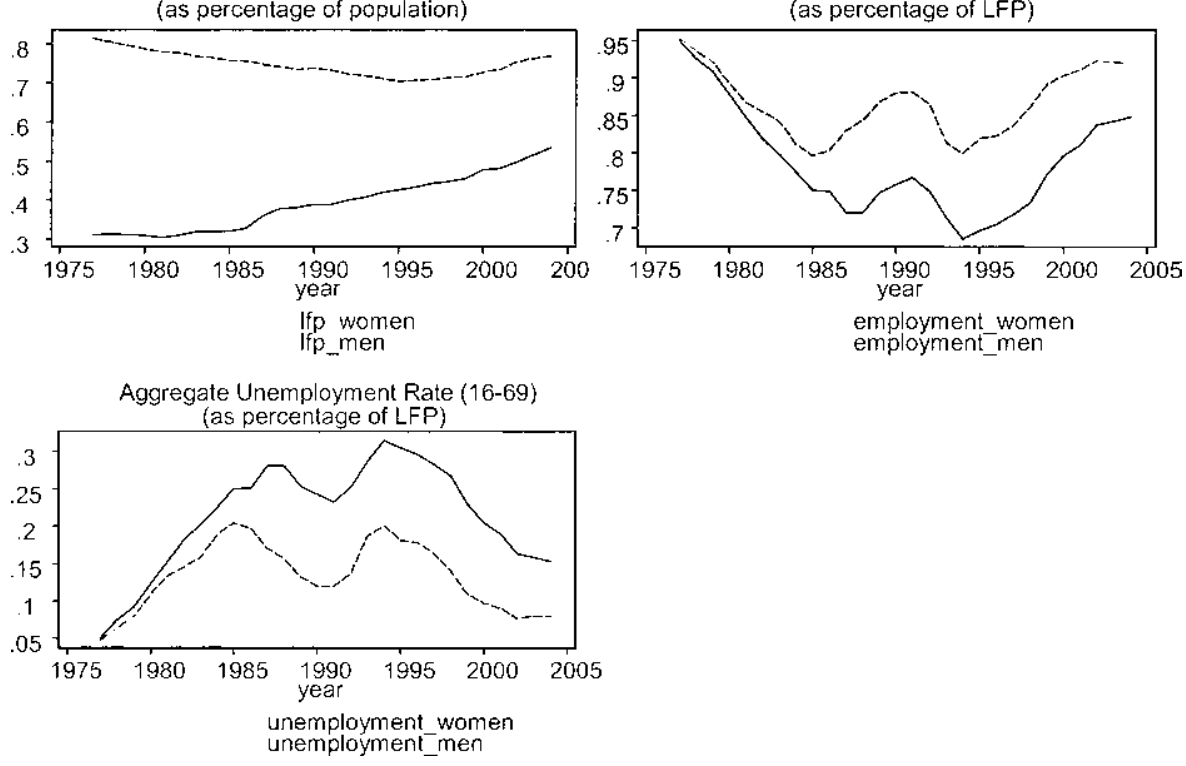

Fig. 9.2 Labor market trends by gender
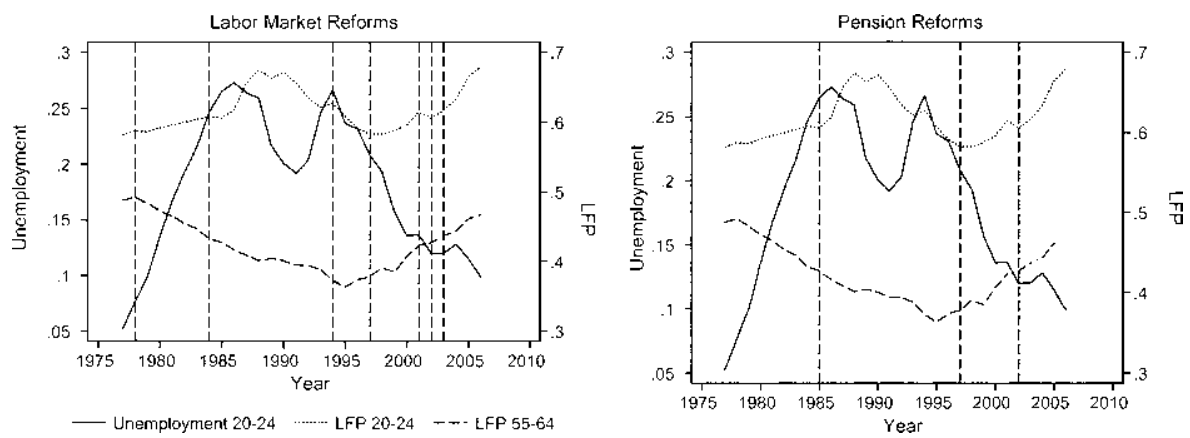

Fig. 9.3 Labor market trends of old and young individuals and labor and pension reforms
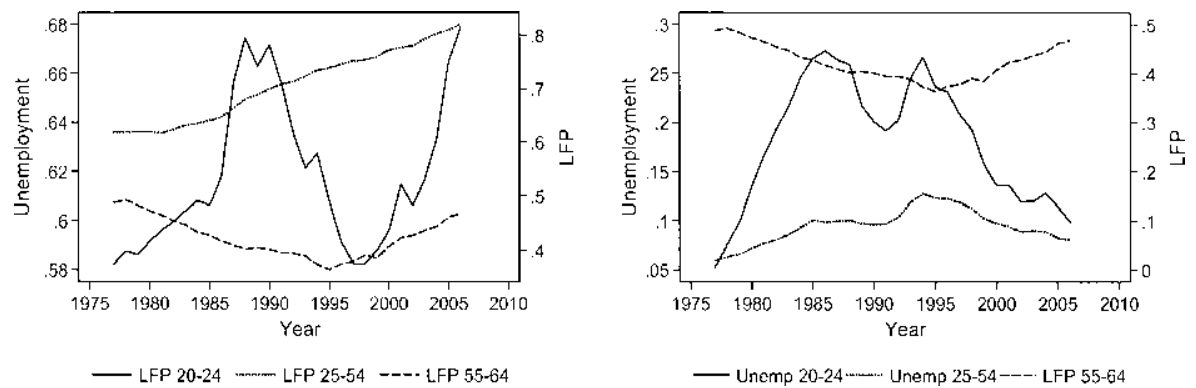

Fig. 9.4 Relationship of young and prime age individuals labor market outcomes and labor force participation of the old 
and prime age individuals behave similarly during the observational period independently on whether we define young individuals to be younger than twenty-five or thirty. However, the unemployment rate of young individuals is always higher. At the same time, the figures show that there is no clear association between the labor force participation of the older group and the employment or unemployment of the other two groups. Moreover, the observed changes in this association are hard to relate with any specific policy change.

To highlight the importance of employment and unemployment for the labor force participation of older workers, figures 9.5, 9.6, and 9.7 show the labor force participation, the employment rate, and the unemployment rate for four different age groups by gender. The behavior of both the labor force participation and the employment rate is more stable during the period than the unemployment rate. We observe a decrease in both the LFP and the employment rate of individuals aged older than sixty, and a slight increase of the same measures for women aged fifty to fifty-four.

On the other hand, there has also been an important increase on the schooling rates of the Spanish population during the period under study. Figure 9.5 shows the percentage of individuals aged twenty to twenty-four who are unemployed, employed, or in school. First notice that the total amount can exceed 100 percent as there can be some individuals who are either employed or unemployed while in school. It can be appreciated that while there has been a decrease in the percentage of young individuals in

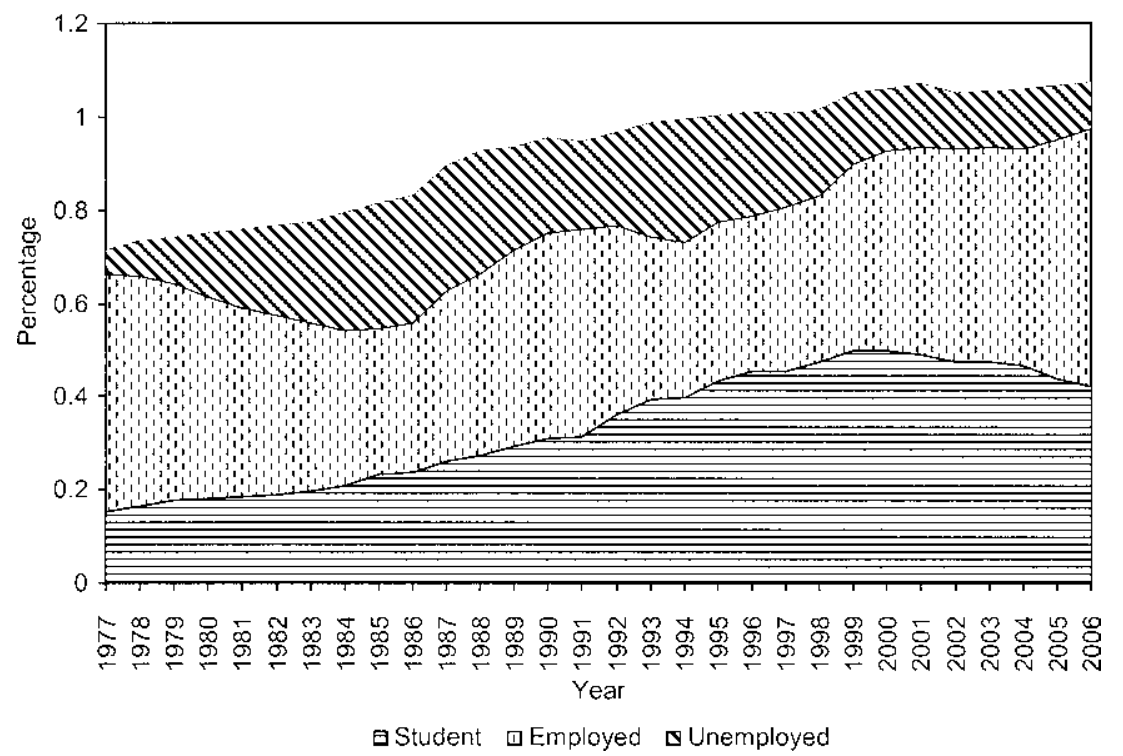

Fig. 9.5 Labor and schooling trends of young individuals in Spain, 1977-2006 
unemployment and an increase in the percentage in employment, the biggest change can be seen in the percentage of individuals who declare being still at school, as it increases from less than 20 percent at the beginning of the period to over 40 percent in the last years.

\subsection{Regressions}

As stated before, the main purpose of this paper is to analyze the link between employment for the young and retirement from the labor force of the elderly population, and, in particular, the link between employment of the young and pension system regulations. Following an independent variable (IV) approach, we want to establish whether social security reforms have been set with the purpose to increase availability of jobs for the young and, of course, whether they have been successful.

We begin with ordinary least squares (OLS) regressions of labor market outcomes for nonelderly on labor market outcomes of the "old." With the purpose to examine as broadly as possible the relationship between LFP of the old and employment of the nonold fraction of the population, we consider the following five dependent variables: Unemployment and Employment for prime age (individuals aged twenty-five to fifty-four) and Unemployment, Employment, and Schooling for the youth (individuals aged twenty to twenty-four). The independent variable is the LFP of the old workers (individuals aged fifty-six to sixty-four). And all the variables are expressed as rates over total population of the relevant age group. We consider two versions of such regressions: levels and differences of order 5 . Let us first introduce the levels regression:

$$
Y_{t}=\alpha+\beta \mathrm{LFPO}_{t}+\delta X_{t}+\varepsilon_{t},
$$

where $Y$ denotes either Employment, Unemployment, or Schooling, and $X$ is a set of economic controls (per capita GDP, GDP growth, and share of manufacturing in GDP) in order to control for labor market characteristics associated with both LFP of the old and employment or unemployment of either young or prime age individuals. The five-year differences equation to be estimated is analogous, but both independent and dependent variables are expressed as a five-year difference.

In summary, for each dependent variable, we carry out the following exercises: levels and differences; two age groups (young and prime age), with and without the selected covariates.

\subsection{Measures of Retirement Incentives}

However, as stated in the introduction, there can be some further labor market conditions beyond social security incentives that can affect both the labor force participation of the older workers and the employment and 
unemployment situation of either young or prime age workers. In order to solve this limitation, we construct a synthetic measure of the incentives faced by older workers.

The purpose of this section is to present the methodology and the assumptions made to construct a synthetic measure of the (monetary or financial) inducement to retirement that the population at retirement risk faces. That is we want to have an aggregate measure of the strength with which the social security spells out representative workers from the labor force. We want this index to account for the various factors influencing retirement decisions: the eligibility age, the benefit level given eligibility, and the change in the benefit if the receipt of benefits is delayed (the idea of the OV (Stock and Wise 1990) and the PV (Coile and Gruber 2000), essentially the actuarial adjustment if retirement is delayed). In order to do so, we first present the standard monetary incentives measures (Gruber and Wise 1999). Then we present the synthetic indicator(s) and the assumptions made in computations.

\subsubsection{Social Security Incentives Measures}

For a (representative) worker of age $a$, following Gruber and Wise (1999), we define social security wealth (SSW) in case of retirement at age $b \geq a$ as the expected present value of future pension benefits:

$$
\mathrm{SSW}_{h}=\sum_{s=h+1}^{S} \rho_{s} B_{s}(h) .
$$

Here $S$ is the age of certain death, $\rho_{s}=\beta^{s-a} \pi_{s}$, with $\beta$ denoting the pure time discount factor and $\pi_{s}$ the conditional survival probability at age $s$ for an individual alive at age $a$, and $B_{s}(h)$ the pension expected at age $s \geq h+1$ in case of retirement at age $s$.

Given SSW, we define three incentive variables for a worker of age $a$ : the accrual at horizon 1 (SSA), the implicit tax/subsidy rate (TAX), the optimal horizontal peak value (PV), and the option value (OV). The definition of these incentive measures, for an individual of age $t=55, \ldots, 69$ are as follows:

- Accrual at horizon 1: $\mathrm{SSA}_{t}=\mathrm{ssw}_{t+1}-\mathrm{ssw}_{t}$.

- Implicit tax/subsidy rate: $\operatorname{TAX}_{t}=\mathrm{SSA}_{t} / E_{t}\left(w_{t+1}\right)$, where $E_{t}$ is the expectation operator based upon the information available up to time $t$.

- Accrual at the optimal horizon $h^{*}$ or peak value: $\mathrm{PV}_{t}=\max _{h}\left(\operatorname{ssw}_{t+h}\right)$ $-\operatorname{ssw}_{t}, h=1, \ldots, R-t$, where $R$ is the mandatory retirement age (the latter does not exist in Spain, but given the retirement evidence, we find it reasonable to assume that $R=70$ ).

- Option Value $\mathrm{OV}_{a}=\max _{h}\left(V_{h}-V_{a}\right), h=a+1, \ldots, R$, where

$$
V_{h}=\sum_{s=a+1}^{h} \rho_{s} W_{s}^{\gamma}+\sum_{s=h+1}^{S} \rho_{s}\left[k B_{s}(h)\right]^{\gamma},
$$


and $p_{s}$ is the survival probability, $S$ is age of (certain) death, $W$ stands for earnings, and $B$ stands for pension benefits.

We have imposed that $\beta=.97, \gamma=1$, and $k=1.25$. Note that under these assumptions:

$$
V_{h}=\sum_{s=a+1}^{h} \rho_{s} W_{s}+1.25 \mathrm{SSW}_{h} .
$$

\subsubsection{A Summary Measure of the Incentive to Retire}

To obtain such an index can become somewhat complicated, especially recognizing the need to account for the key aspects of the inducement to retire: the age of eligibility, the benefit level given eligibility, and the change in the benefit if the receipt of benefits is delayed (the OV/PV idea, essentially the actuarial adjustment if retirement is delayed). Here, we consider the development of a summary measure of the inducement to retire. We begin with a suggested summary measure of the inducement implicit in the present value of social security benefits. Then we discuss how this sort of measure might be extended to develop a single summary measure that incorporates each of the three aspects of the inducement to retire.

We will be using the incentive measure in time series regressions, so we need to think about the inducement to retire with respect to all older persons who are out of the labor force in a given year. We will consider several alternatives.

First, we want to summarize the SSW faced by persons who are out of the labor force in year $t$. For simplicity, we assume a rather narrow age range for illustration, but the actual age range could be much broader. Assume the first eligibility age is fifty-five. Consider the "average" social security wealth $W$ of all persons aged fifty-five to $R(R=70$, for example) retired in 1980. Those fifty-five in 1980 must have retired in 1980, and we want the $W$ of fifty-five-year-olds in 1980. Those fifty-six in 1980 could have retired at fifty-five in 1979 or at fifty-six in 1980 , so we need $W(55,1979)$ and $W(56$, $1980)$. And we need to weight these wealth numbers by $q(55,1979)$ and $q(56$, 1980), where $q$ measures the odds of exposure to those retirement incentives at each age/year. Those fifty-seven in 1980 could have retired at fifty-five in 1978 , or fifty-six in 1979 , or at fifty-seven in 1980 . So we need $W(55,1978)$, $W(56,1979)$, and $W(57,1980)$. And we need to weight these wealth numbers by $q(55,1978), q(56,1979)$, and $q(57,1980)$, respectively.

So, in general, when we consider all feasible retirement ages,

$$
\bar{W}(y)=\left[\sum_{a=55}^{R} \frac{P(a, y)}{\sum_{b=55}^{R} P(b, y)}\right]\left[\frac{\sum_{t=0}^{a-55} W(a-t, y-t) q(a-t, a-t)}{\sum_{t=0}^{a-55} q(a-t, a-t)}\right],
$$

where $R=64, P(a, y)$ is the proportion of retired persons at age $a$ in year $y$ and $q(a, y)$ is the labor force participation of person of age $a$ in year $y$. 


\subsubsection{A More General Inducement Measure}

The disadvantage of the approach laid out in the preceding is that it captures only one of the three aspects of the inducement to retire (the benefit level), while ignoring two others (the first eligibility age and the PV/OV). We would like to consider a more inclusive index that captures all three aspects of how social security systems affect retirement as well as discounting of future benefits. The generalized inducement to retirement measure, $\bar{I}$ is constructed by replacing $W(a ; y)$ in the preceding formula by:

$$
I(a, y, \alpha)=W(a, y)+\alpha[W(a, y)-\operatorname{PV}(a, y)],
$$

where $0 \leq \alpha \leq 1$ is a discounting factor that may vary with age. Note that when $\alpha=1$, the same weights are given to the terms $W(a, y)$ and $W(a, y)-$ $\operatorname{PV}(a, y)$, and, when $\alpha=0$, we get the $W$ index. Note the eligibility is taken into account, under borrowing constraints, by setting $W(a, y)$ equal to zero for those ages in which the individual is not eligible to retirement. So, finally, we get the following formula:

$$
\bar{I}(y)=\left[\sum_{a=55}^{R} \frac{P(a, y)}{\sum_{b=55}^{R} P(b, y)}\right]\left[\frac{\sum_{t=0}^{a-55} I(a-t, y-t) q(a-t, a-t)}{\sum_{t=0}^{a-55} q(a-t, a-t)}\right]
$$

\subsubsection{Assumptions Made in Incentives Calculus}

We compute social security incentives for stylized individuals representing cohorts born between 1910 (age seventy in 1980) and 1970 (age thirty-five in 2005). In order to compute the preceding incentives, we need several ingredients: wage and contributions history and family characteristics.

As regards wage and contributions history, we proceed as follows:

- From every year-of-birth and gender cohort in the ECVL2006 sample, we construct (when available) the median wage distribution in the period 1981 to 2005. For example, for the group of individuals born in 1940, we recover covered wages from age forty-one to sixty-five. In general for individuals born in year $j$ we recover wages from ages $1981-j$ to $2005-j$.

- Given this information, we regress the observed data against age and its square and region.

- Then we predict backward and forward in order to obtain a complete year of birth-gender-region wage profiles in the twenty to seventy age range.

- We consider that the representative individual has contributed for thirty years at age fifty-five, that is, they have contributed for thirty-five years at sixty (the early retirement age) and forty by age sixty-five (the normal retirement age). 
Regarding the family and other characteristics, we assume:

1. For the male cohorts in sample, we initially assume that (a) they are married with a nonworking spouse, (b) their wife is three years younger, and (c) their mortality corresponds to the baseline male mortality from the official data (INE 1995).

2. For every female cohort in sample, we initially assume that (a) they are married with a retiree or a worker entitled to retirement benefits, (b) their husband is four years older, and (c) their mortality is the baseline female mortality from official data (INE 1995).

3. In addition, for both men and women, we assume that (d) starting at age fifty-five and until a person reaches sixty-five, there are three pathways into retirement: unemployment benefits for individuals older aged at least fifty-two (UB52+), disability insurance (DI) and early retirement (ER). At each particular age, the individual has an age-specific probability of going into retirement using any of these three programs. However, we have to take into account the following restrictions.

As for eligibility, we assume:

1. A person has no access to the ER program before age sixty.

2. After age sixty, a person cannot claim UB52+ and can only claim ER or DI benefits.

Finally, the participation and employment rates, as well as the fraction of retirees, are obtained from the Encuesta de Población Activa (EPA) in the period 1977 to 2006 . Moreover, we have used the relative male/female employment rates to build up gender-aggregated incentive measures.

\section{Combining Several Programs}

Figure 9.6 shows the percentage of individuals aged fifty-five to sixtyfour that have most likely exit from the labor force, either through normal retirement, disability, or unemployment schemes. It can be seen that the percentage that exits through other routes rather than normal retirement is nonnegligible; thus, in order to estimate a summary measure of the incentives faced by older workers in order to exit their employment, we should also include the incentives that come from other sources.

We would like to weigh the incentives to exit through the different routes using the actual taking rates. Unfortunately, we can only observe the percentage of individuals that are at each state each year, so we have approximated the corresponding weights as follows. We have first selected those individuals who are either employed, unemployed, or on a disability scheme. Then the weight assigned to SSW (normal retirement) is equal to the percentage that employed individuals represent on this selected population. Accordingly, the weight assigned to SSW (unemployment) has been approximated by the 


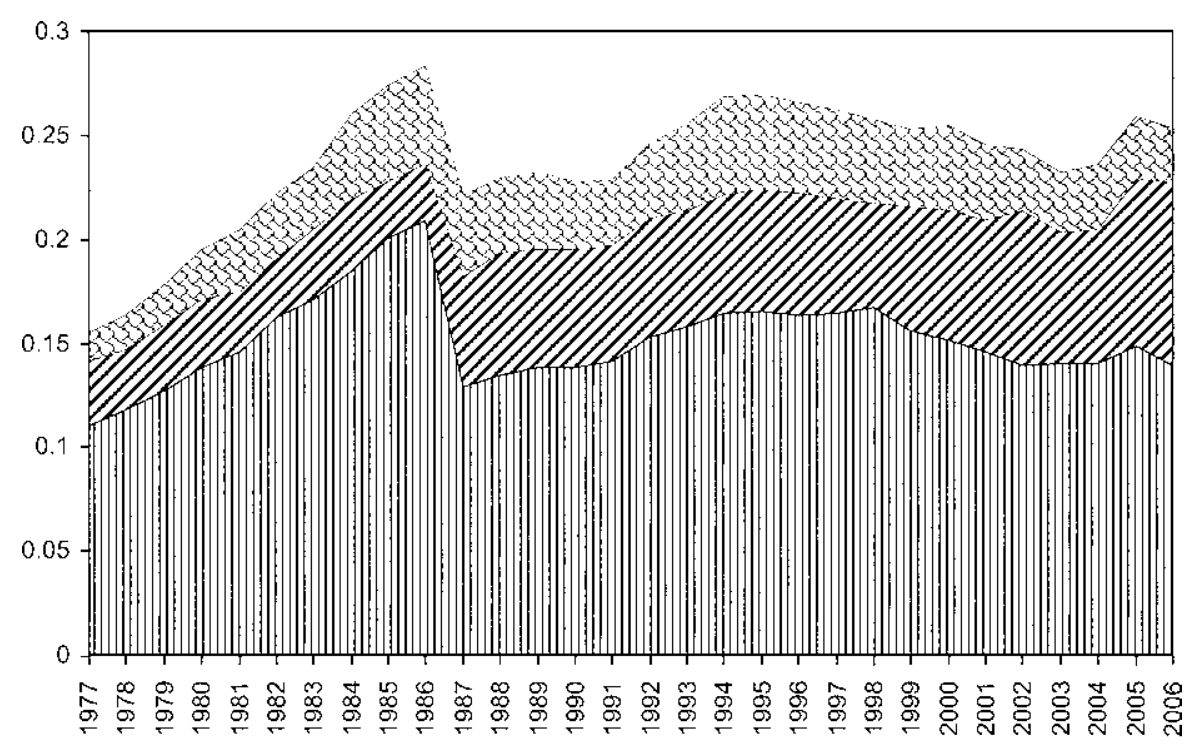

$\square$ Percentage retirement $\square$ Percentage disability : : Percentage unemployment

Fig. 9.6 Percentage of individuals aged fifty-five to sixty-four that declare to be retired, unemployed, or in a disability scheme

proportion that unemployed individuals represent on that population and the weight assigned to SSW (disability) as the proportion that individuals on a disability scheme represent on this selected population. We have further restricted the probability of receiving unemployment SSW to zero for individuals older than sixty and calculate two different indexes depending on whether retirement wealth was assumed to be zero earlier than the retirement age.

\subsubsection{Description of Variation}

Figure 9.7 presents the time trend of the incentive variable $\bar{I}$ assuming that alpha equals 2.5 under different assumptions regarding on one hand the effects of different routes into retirement and on the other the value of pension social security wealth before the legal retirement age of sixty. The first index (Ibar250_1) assumes that pension social security wealth before the age of sixty equals 0 and that there is only normal retirement as a route into retirement. The different assumption in the second index (Ibar250_2) is that wealth before age of sixty is different from zero. Both the third (Ibar250_3) and the fourth (Ibar250_4) indexes include different routes into retirement, but while the third assumes that social security wealth before the age of sixty is equal to 0 , the fourth doesn't. 


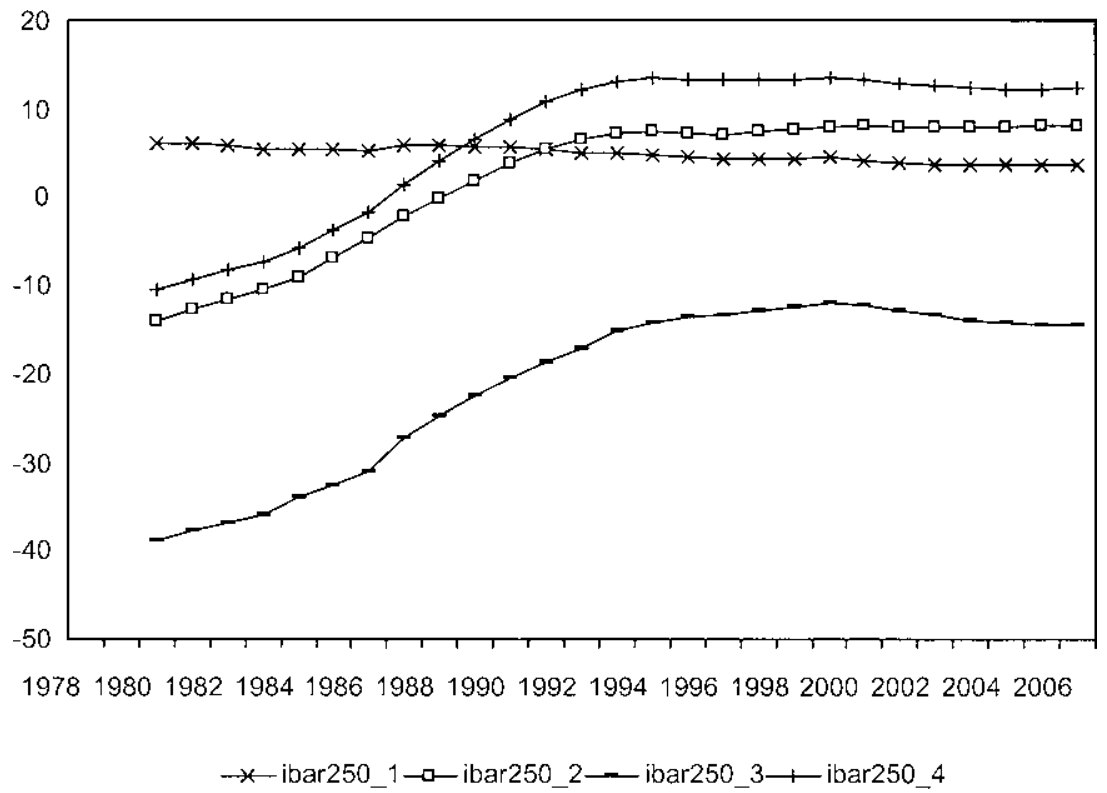

Fig. 9.7 Trends of Ibar under different assumptions on routes into retirement

\subsubsection{Incentives Regression}

In addition to the relationship between the employment of the old and the unemployment of the young, as described in the preceding, we would like to estimate the direct relationship between the inducement for the old to leave the labor force and the employment of the young. So we add to the regressions the synthetic measure of the inducement to retirement. In this case, the model to be estimated is the following:

$$
Y_{t}=\alpha+\beta \bar{I}_{t}+\delta X_{t}+\varepsilon_{t}
$$

\subsection{Results}

We finally come to the empirical findings. In order to test whether the old and young Spanish workers are complement or substitute, we follow a two-step procedure. In the first step, we test if there is any direct relationship between the labor force participation of the old and the employment and unemployment levels of the young. We estimate both sets of regressions in levels and in five-year differences, with and without covariates to control for the economic cycle. In the second step, we analyze how the incentives to retire faced by the old directly influence the employment outcomes of the young. However, before obtaining the second set of estimates, we compute 
empirically the value of alpha to be used to weigh the two components of the $I$-index. The analysis is carried out using data aggregated to the cells in the period 1977 to $2006(N=30)$.

\subsubsection{Direct Effects of LFP of the Old}

Table 9.3,9.4, and 9.5 report the results about the direct effect of the labor supply of older workers on the employment outcomes of the young; the models have been estimated in levels and in fifth differences. The evidence is mixed, although it mostly rejects the substitutability hypothesis. On the other hand, the complementarity hypothesis is also rejected in some specifications, especially when the full set of economic covariates is included.

On the basis of this evidence, one could argue that there exists a positive relationship between the labor force participation of older workers and the employment rate of prime age individuals, while the association between unemployment and labor force participation is negative. Moreover, there is no evidence supporting the hypothesis that old and young workers are substitute; if anything, they are complement.

One may argue that, in Spain, the entry into active labor market participation takes place later than in most countries; hence, individuals aged twenty-five to twenty-nine should be treated as "young" and not considered within the prime age group. In order to test the sensitivity of our results to age grouping, we have replicated the analysis treating people from twenty to twenty-nine as young and redefining the prime age group accordingly (thirty to fifty-four). The results are shown in table 9.4 and are consistent with those in table 9.3.

The results shown in table 9.5 exploit the regional variations available in

Table 9.3

Estimates of the direct effect (older [55+] workers labor force participation)

\begin{tabular}{|c|c|c|c|c|c|c|}
\hline & \multicolumn{3}{|c|}{ Levels } & \multicolumn{3}{|c|}{ 5-year differences } \\
\hline & Coefficient & SE & $R^{2}$ & Coefficient & SE & $R^{2}$ \\
\hline \multicolumn{7}{|c|}{ Covariates: GDP per capita, GDP growth, \% manufactures } \\
\hline Employment young & 0.809 & 0.301 & 0.738 & -0.477 & 0.284 & 0.338 \\
\hline Unemployment young & 0.298 & 0.329 & 0.888 & 0.618 & 0.292 & 0.325 \\
\hline Students & -1.981 & 0.350 & 0.964 & -0.171 & 0.365 & 0.287 \\
\hline Employment prime & 0.437 & 0.077 & 0.988 & -0.271 & 0.077 & 0.679 \\
\hline Unemployment prime & -0.609 & 0.127 & 0.918 & 0.422 & 0.063 & 0.6346 \\
\hline \multicolumn{7}{|c|}{ No covariates } \\
\hline Employment young & 1.061 & 0.194 & 0.378 & -0.378 & 0.282 & 0.058 \\
\hline Unemployment young & -1.176 & 0.168 & 0.477 & 0.391 & 0.314 & 0.048 \\
\hline Students & -1.736 & 0.370 & 0.311 & 0.108 & 0.346 & 0.006 \\
\hline Employment prime & 0.195 & 0.265 & 0.014 & -0.272 & 0.083 & 0.283 \\
\hline Unemployment prime & -0.900 & 0.052 & 0.911 & 0.354 & 0.084 & 0.289 \\
\hline
\end{tabular}

Notes: $\mathrm{SE}=$ standard error. 
Estimates of the direct effect (older [55+] workers labor force participation)

\begin{tabular}{|c|c|c|c|c|c|c|}
\hline & \multicolumn{3}{|c|}{ Levels } & \multicolumn{3}{|c|}{ 5-year differences } \\
\hline & Coefficient & SE & $R^{2}$ & Coefficient & SE & $R^{2}$ \\
\hline \multicolumn{7}{|c|}{ Covariates: GDP per capita, GDP growth, \%manufactures } \\
\hline Employment young & 0.734 & 0.194 & 0.896 & -0.456 & 0.170 & 0.674 \\
\hline Unemployment young & -0.143 & 0.260 & 0.905 & 0.611 & 0.190 & 0.517 \\
\hline Students & -1.653 & 0.300 & 0.953 & -0.359 & 0.397 & 0.146 \\
\hline Employment prime & 0.425 & 0.074 & 0.991 & -0.221 & 0.087 & 0.434 \\
\hline Unemployment prime & -0.603 & 0.112 & 0.910 & 0.413 & 0.066 & 0.651 \\
\hline \multicolumn{7}{|c|}{ No covariates } \\
\hline Employment young & 0.828 & 0.251 & 0.199 & -0.548 & 0.178 & 0.220 \\
\hline Unemployment young & -1.296 & 0.129 & 0.652 & 0.493 & 0.224 & 0.121 \\
\hline Students & -1.271 & 0.261 & 0.324 & -0.034 & 0.398 & 0.001 \\
\hline Employment prime & 0.134 & 0.266 & 0.007 & -0.184 & 0.088 & 0.131 \\
\hline Unemployment prime & -0.783 & 0.051 & 0.890 & 0.319 & 0.082 & 0.282 \\
\hline
\end{tabular}

Notes: $\mathrm{SE}=$ standard error.

Table 9.5 Estimates of the direct effect (older [55+] workers labor force participation) exploiting regional variation

\begin{tabular}{|c|c|c|c|c|c|c|}
\hline & \multicolumn{3}{|c|}{ Levels } & \multicolumn{3}{|c|}{ 5-year differences } \\
\hline & Coefficient & SE & $R^{2}$ & Coefficient & $\mathrm{SE}$ & $R^{2}$ \\
\hline \multicolumn{7}{|c|}{ Covariates: GDP per capita, GDP growth, \%manufactures } \\
\hline Employment young & 0.541 & 0.238 & 0.290 & 0.017 & 0.134 & 0.073 \\
\hline Unemployment young & -0.460 & 0.093 & 0.541 & 0.044 & 0.120 & 0.047 \\
\hline Students & -0.403 & 0.245 & 0.709 & -0.150 & 0.127 & 0.042 \\
\hline Employment prime & 0.534 & 0.063 & 0.889 & 0.060 & 0.044 & 0.035 \\
\hline Unemployment prime & -0.343 & 0.099 & 0.486 & -0.029 & 0.036 & 0.041 \\
\hline \multicolumn{7}{|c|}{ No covariates } \\
\hline Employment young & 0.682 & 0.231 & 0.217 & 0.061 & 0.083 & 0.002 \\
\hline Unemployment young & -0.618 & 0.139 & 0.280 & -0.051 & 0.092 & 0.002 \\
\hline Students & -0.737 & 0.174 & 0.127 & -0.025 & 0.078 & 0.000 \\
\hline Employment prime & 0.444 & 0.099 & 0.130 & 0.051 & 0.045 & 0.009 \\
\hline Unemployment prime & -0.434 & 0.101 & 0.429 & -0.010 & 0.032 & 0.001 \\
\hline
\end{tabular}

Note: See table 9.3 notes.

Spain. We estimate the previous models (in levels and in five-year differences, with and without covariates) using information at the autonomous communities level. The results are consistent with the evidence reported previously. Once again, the evidence differs depending on the set of results analyzed (levels versus five-year differences), but the $R^{2}$ values suggest a better fit from the equation in levels. In this case, we can see that, regardless of the use of covariates, the evidence suggests a positive association between employment of the young and of prime age individuals and the labor force participation 
Estimates of the indirect effect (coefficients of the incentive variable $\bar{I}$ )

\begin{tabular}{|c|c|c|c|c|c|c|}
\hline & \multicolumn{3}{|c|}{ Levels } & \multicolumn{3}{|c|}{ 5-year differences } \\
\hline & Coefficient & $\mathrm{SE}$ & $R^{2}$ & Coefficient & SE & $R^{2}$ \\
\hline \multicolumn{7}{|c|}{ Covariates: GDP per capita, GDP growth, \%manufactures } \\
\hline LFP older & -0.005 & 0.000 & 0.984 & -0.006 & 0.004 & 0.228 \\
\hline Employment young & -0.001 & 0.002 & 0.723 & 0.019 & 0.003 & 0.670 \\
\hline Unemployment young & -0.002 & 0.002 & 0.888 & -0.025 & 0.003 & 0.750 \\
\hline Students & 0.010 & 0.002 & 0.953 & 0.003 & 0.004 & 0.2875 \\
\hline Employment prime & -0.002 & 0.001 & 0.987 & 0.004 & 0.001 & 0.565 \\
\hline Unemployment prime & 0.003 & 0.001 & 0.910 & -0.004 & 0.002 & 0.398 \\
\hline \multicolumn{7}{|c|}{ No covariates } \\
\hline LFP older & -0.002 & 0.000 & 0.286 & -0.002 & 0.003 & 0.020 \\
\hline Employment young & 0.002 & 0.001 & 0.104 & 0.011 & 0.004 & 0.214 \\
\hline Unemployment young & -0.002 & 0.001 & 0.100 & -0.012 & 0.005 & 0.207 \\
\hline Students & 0.011 & 0.001 & 0.9176 & 0.008 & 0.003 & 0.138 \\
\hline Employment prime & 0.005 & 0.001 & 0.462 & 0.001 & 0.001 & 0.010 \\
\hline Unemployment prime & 0.002 & 0.000 & 0.269 & -0.001 & 0.002 & 0.010 \\
\hline
\end{tabular}

Notes: Definitions of population groups: young $=20-24$; prime $=25-54 ;$ ERA $=$ earle retirement age; older $=55+$. Assumptions: $\alpha=2.5$ and $\gamma=1$, pre-ERA wealth is set to zero and combining exit routes. $\mathrm{SE}=$ standard error; LFP $=$ labor force participation.

of the old. The same is true for the unemployment rates of these two age groups. Moreover, the percentage of students in the young group is also negatively associated with the labor force participation of the old.

\subsubsection{Effects from the Incentives to Retire}

Table 9.6 presents the key result from the analysis both in levels and fiveyear differences. First, results vary substantially depending of the specification (levels or five years differences). Second, the Ibar variable is much more significant in the specification in levels (with and without covariates). Third, in the specification with covariates, the incentive variable works in the correct direction for the LFP of the old, and it is insignificant for the behavior of the young. On the other hand, in the specification with no covariates, the effect of the incentive variable indicates substitutability between the young and the old workers.

\subsection{Conclusions}

The Spanish pension system has witnessed relatively few changes during the period 1975 to 2005 . In fact, only the changes in the pension formula introduced in 1985 are of some relevance. The recent reform (2002, further modified in 2007) introduced some important changes, but the key ones are to be phased out during several years, and a very large fraction of the active 
workers can still retire under the 1997 rules. This is particularly true for the change in the ERA (from sixty to sixty-one).

The most important changes have been the increase in the generosity of both the minimum and survival pensions, and the introduction (in 1990) of noncontributive pensions. However, these changes only affect the lowskilled workers, which are, in practice, scarcely substitutable by younger, and usually much more educated, workers. The pension incentives faced by the average and high earners, who are relatively more substitutable by the educated young, have remained relatively stable since 1985 .

This defines a context of "unimportant" reforms (except, perhaps, for the 2006/2007 changes that we cannot study), which severely limits the variation in data. Either for this reason or because there is actually no correlation whatsoever between the two variables, we have found only some (very weak) evidence of a positive relationship between the employment level of the young and the exit from the labor force of older workers.

An interesting potential avenue for further analysis may be the consideration of the regional dimension of the Spanish labor market, which is likely to introduce substantial additional variation in the data.

\section{Appendix}

\section{The Spanish Pension System since 1985}

The rules governing the old age and survivors pensions in the RGSS in 1985 are described in the following. The changes introduced by the 1997 reform (R97) and the 2002 (A02) amendment will be illustrated as we go along. A summary of the basic technical aspects of the pre- and post-1997 systems can be found in table 9A.2.

\section{Financing and Eligibility}

The RGSS is a pure pay-as-you-go scheme. Contributions are a fixed proportion of covered earnings, defined as total earnings, excluding payments for overtime work, between a floor and a ceiling that vary by broadly defined professional categories. Currently, eleven categories are distinguished, each one with its own ceiling and floor for covered earnings. The current RGSS contribution rate is 28.3 percent, of which 23.6 percent is attributed to the employer and the remaining 4.7 percent to the employee. A tax rate of 14 percent is levied on earnings from overtime work.

Entitlement to an old age pension requires at least fifteen years of contributions. As a general rule, recipiency is conditional on having reached age sixty-five and is incompatible with income from any kind of employment requiring affiliation to the social security system. 


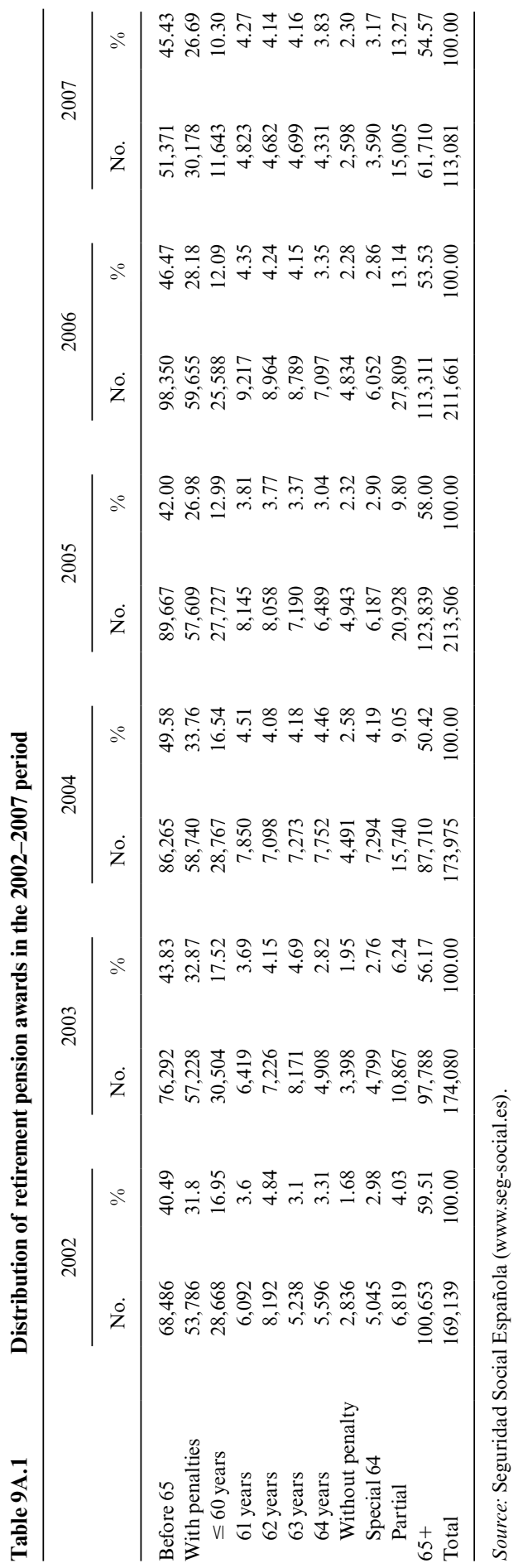




\section{Benefit Computation}

When eligibility conditions are met, a retiring worker receives an initial monthly pension, $P_{t}$, equal to

$$
P_{t}=\alpha_{n} \mathrm{BR}_{t}
$$

where the benefit base (base reguladora) $\mathrm{BR}_{t}$ is a weighted average of covered monthly earnings over a reference period that consists of the last eight years before retirement until the 1997 reform. Therefore, the $\mathrm{BR}_{t}$ using eight years as the number of contributed years is calculated as:

$$
\frac{1}{96}\left(\sum_{j=1}^{24} B C_{t-j}+\sum_{j=25}^{96} B C_{t-j} \frac{I_{t-25}}{I_{t-j}}\right)
$$

where $W_{t-j}$ and $I_{t-j}$ are earnings and the consumer price index in the $j$ th month before retirement. Pensions are paid in fourteen annual installments, hence the division by 112 in the previous formula. The replacement rate $\alpha_{n}$ depends on the age of the retirees and on the number of years of contribution. When age is below sixty, $\alpha_{n}=0$ for all $n$. For age equal or greater than sixty-five, $\alpha_{n}$ is equal to

$$
\alpha_{n}= \begin{cases}0, & \text { if } n<15 \\ .6+.02(n-15), & \text { if } 15 \leq n<35 \\ 1, & \text { if } 35 \leq n\end{cases}
$$

In the case of early retirement, that is, for ages between sixty and sixtyfive, $\alpha_{n}$ is determined by the previous formula multiplied by a penalization factor. The latter is equal to 0.60 at sixty, and increases of .08 each year, until reaching the value of 1.0 at age sixty-five.

$$
\mathrm{BR}_{t}=\frac{1}{112}\left(\sum_{j=1}^{24} W_{t-j} \sum_{j=25}^{96} W_{t-j} \frac{I_{t-25}}{I_{t-j}}\right)
$$

Beginning in 1997, the number of reference years used for computing $\mathrm{BR}_{t}$ has been increased by one every year until 2003, to reach a total of fifteen years. The formula for computing $\alpha_{n}$ has been changed to the following:

$$
\alpha_{n}= \begin{cases}0, & \text { if } n<15 \\ .5+.03(n-15), & \text { if } 15 \leq n<25 \\ .8+.02(n-25), & \text { if } 25 \leq n<35 \\ 1, & \text { if } 35 \leq n .\end{cases}
$$

The penalization factors have, basically, remained the same, with an exception made for workers with forty or more years of contributions (details 


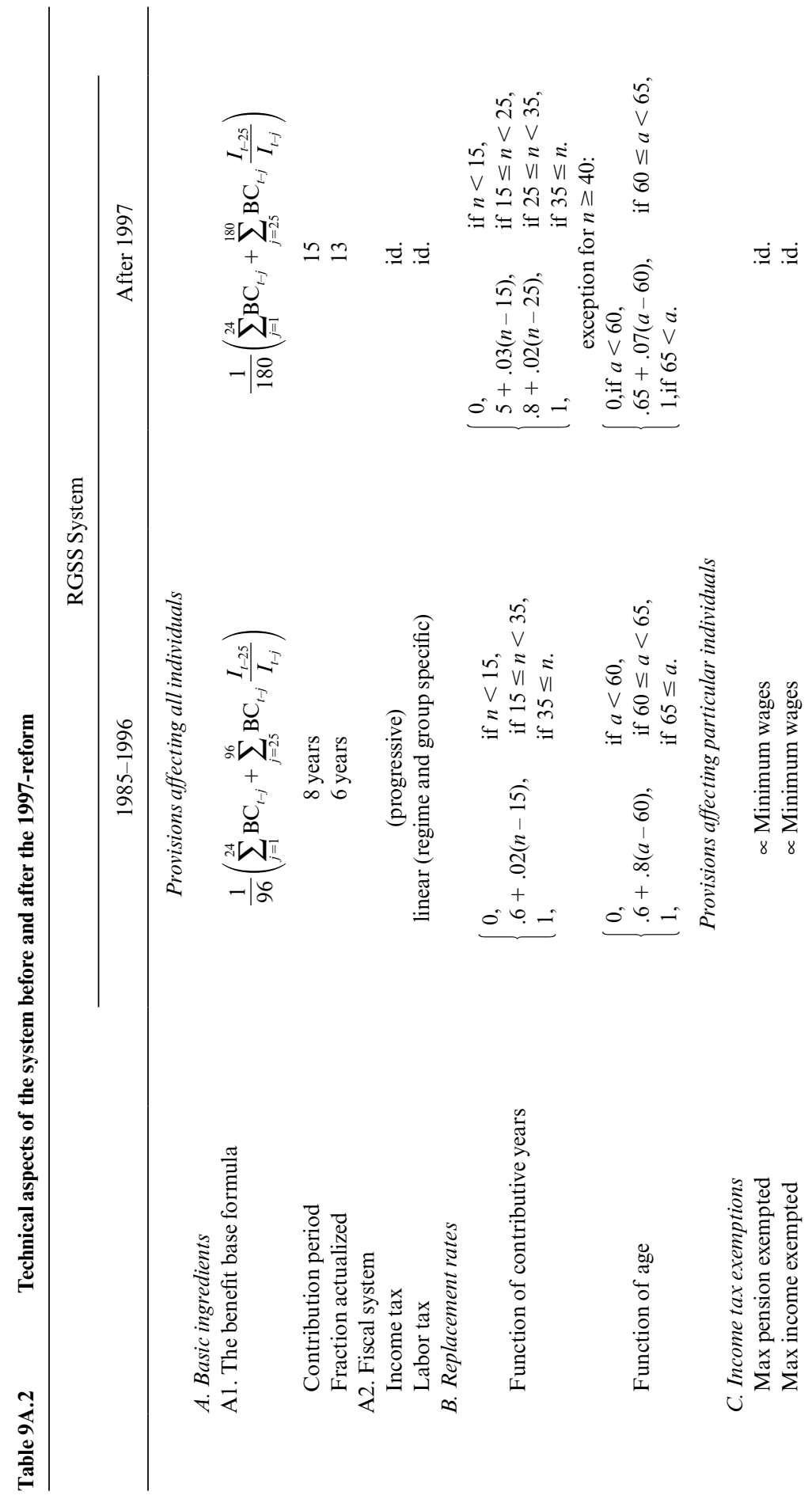



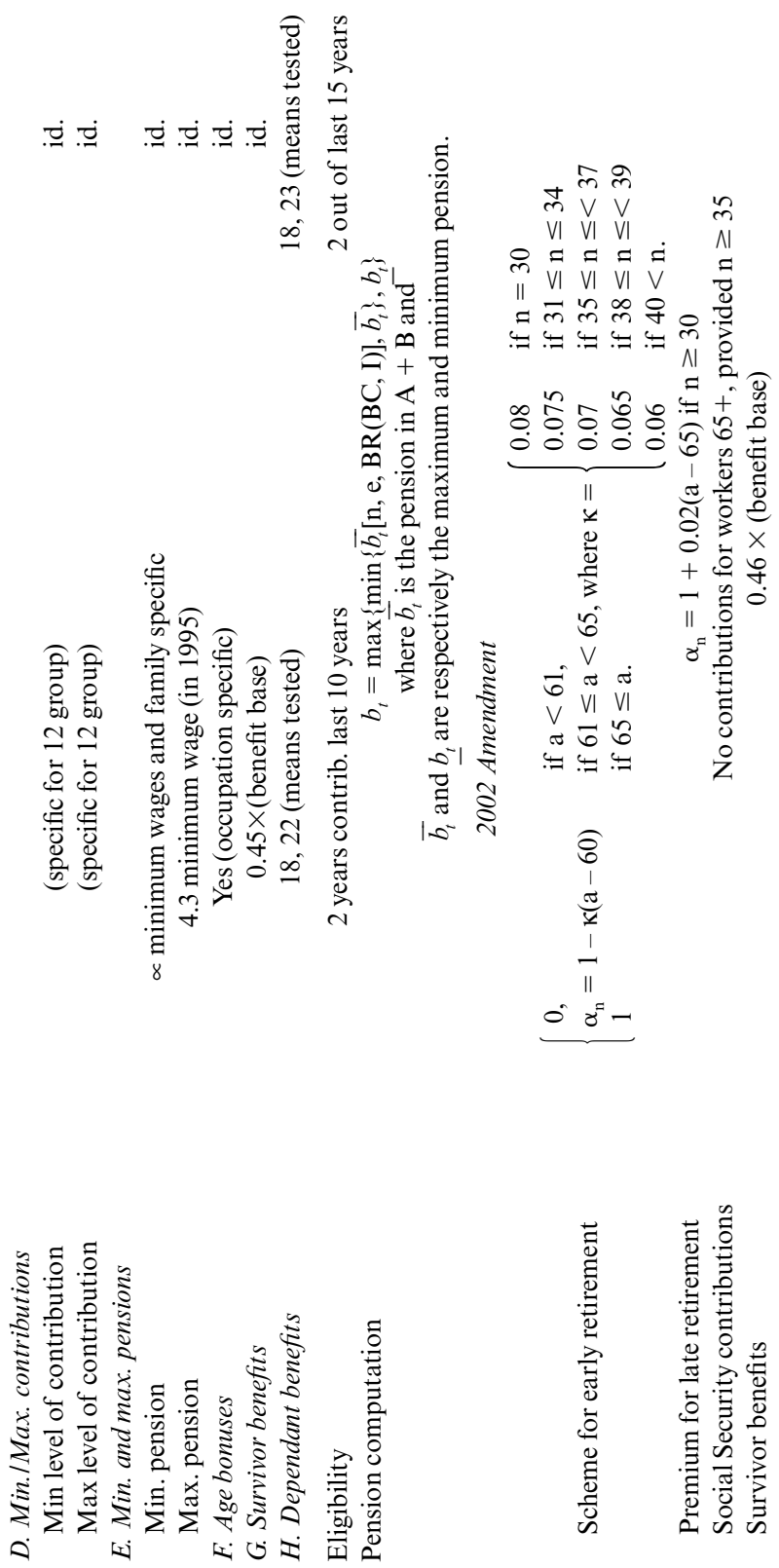
in the next subsection). The A02 amendment allows for the possibility of $\alpha_{n}$ being greater that one when people are above sixty-five years of age, that is,

$$
\alpha_{n}=1+.02(a-65), \quad \text { if } 65 \leq a \text { and } n \geq 35 .
$$

Outstanding pensions are fully indexed to price inflation, as measured by the consumer price index. Until 1986, pensions were also indexed to real wage growth.

\section{Early Retirement}

The normal retirement age is sixty-five but early retirement at age sixty is permitted under fairly common circumstances (sixty-one from the 2002 reform, but phased out to those who have not contributed before January, 1 1967). The replacement rate for early retirees is reduced by 8 percentage points for each year under age sixty-five. Starting from 1997, workers who retire after the age of sixty with forty or more contributive years are charged a penalty of only 7 percent for each year under age sixty-five. The 2002 amendment has modified further the rules determining the replacement rate. It now reads as follows:

$$
\alpha_{n}= \begin{cases}0, & \text { if } a<61 \\ 1-\kappa(a-60), & \text { if } 61 \leq a<65 \\ 1, & \text { if } 65 \leq a,\end{cases}
$$

where

$$
\kappa= \begin{cases}0.08 & \text { if } n=30, \\ 0.075 & \text { if } 31 \leq n \leq 34 \\ 0.07 & \text { if } 35 \leq n \leq 37 \\ 0.065 & \text { if } 38 \leq n \leq 39 \\ 0.06 & \text { if } 40 \leq n .\end{cases}
$$

Unless a collective labor agreement prescribes mandatory retirement, individuals may continue working after age sixty-five. Before 2002 there were no incentives to work past age sixty-five. As mentioned, the 2002 legislation now allows for:

$$
\alpha_{n}=1+.02(a-65), \quad \text { if } 65 \leq a \text { and } n \geq 35
$$

and eliminates social security contributions for workers meeting the eligibility criteria for full normal retirement ( $a \geq 65$ and $n \geq 35$ ) and who continue working. About 10 percent of the workers enrolled in the RGSS are actually exempt from reduction in the replacement rate in case of early retirement. 


\section{Maximum and Minimum Pension}

Pensions are subject to a ceiling, legislated annually and roughly equal to the ceiling on covered earnings. The 2000 ceiling corresponds to about 4.3 times the minimum wage (salario mínimo interprofesional, or SMI) and about 1.6 times the average monthly earnings in the manufacturing and service sectors. If the initial old age pension, computed as in the preceding, is below a minimum, then the minimum pension is paid. The latter is also legislated annually. Other things being equal, minimum pensions are higher for those who are older than sixty-five or have a dependent spouse.

In Spain, the annual value of the minimum guaranteed is discretionarily chosen by the government. In 2005, 2.25 millions of contributory pensions topped up (which represents 28.4 percent of all pensions (21.7 percent in RGSS and 38 percent of RETA, 28.2 percent of all old age pensions (36.5 percent of widowhood). The percentage of RGSS retirees receiving a minimum pension has been declining steadily, from over 75 percent in the late 1970 s to 27 percent in 1995 . The ratio between the minimum old age pension and the minimum wage has been increasing steadily from the late 1970s (it was 75 percent in 1975) until reaching almost 100 percent in the early 1990s. In 2007, the ratio of the minimum benefit for pensioners above +65 (with a dependant spouse) to the minimum wage was 108, or 92 percent of the average pension. The real rate of growth of the minimum pension in 1990/2007 was 1.1 percent and 3.86 in the first term of Zapatero, 2004/2007.

Minimum pensions are also very popular for their redistributive properties: "atendiendo al principio de solidaridad que inspira la redistribución de rentas en el sistema de seguridad social español, los mecanismos establecidos son la garantía de pensión mínima en la esfera contributiva y las pensiones no contributivas" (Spanish Ministry of Labor and Social Affairs 2005).

\section{Family Considerations}

A pensioner receives a fixed annual allowance for each dependent child that is younger than 18 or disabled. In 2000, this allowance was equal to 48,420 pesetas for each child under 18 , and to 468,720 pesetas (45 percent of the annualized minimum wage) for each disabled child.

Survivors (spouse, children, and other relatives) may receive a fraction of the benefit base of the deceased if the latter was a pensioner or died before retirement after contributing for at least 500 days in the last five years. The surviving spouse gets 45 percent of the benefit base of the deceased (46 percent after the 2002 amendment, a fraction that will be increased further in the forthcoming years). Such pension is compatible with labor income and any other old age or disability pension, but is lost is the spouse marries. 
Each of the surviving children gets 20 percent of the benefit base until the age of eighteen (amount raised to 23 percent in 1997). An orphan who is sole beneficiary may receive up to 65 percent of the benefit base. If there are several surviving children, the sum of the pensions to the surviving spouse (if any) and the children cannot exceed 100 percent of the benefit base.

A Spanish peculiarity is the "pension in favor of family members." This pension entitles other surviving relatives (e.g., parents, grandparents, siblings, nephews, etc.) to 20 percent of the benefit base of the principal if they satisfy certain eligibility conditions (older than forty-five, do not have a spouse, do not have other means of subsistence, have been living with and depending economically upon the deceased for the last two years). To this pension, one may add the 45 percent survivors pension if there is no surviving spouse or eligible surviving children.

\section{Rules for the Self-Employed}

In this section, we sketch the main differences between the RGSS and the RETA. Beside differences in the Social Security tax rate and the definition of covered earnings, the people affiliated to RETA and who are not miners or sailors have no early retirement option.

While the Social Security tax rate is the same for the RETA and the general scheme (28.3 percent in 2000), covered earnings are computed differently, as the self-employed are essentially free to choose their covered earnings between a floor and a ceiling legislated annually. Not surprisingly, in light of the strong progressivity of Spanish personal income taxes, a suspiciously large proportion of self-employed workers report earnings equal to the legislated floor until they reach about age fifty to fifty-five. After that age, one observes a sudden increase in reported covered earnings. This behaviors exploits the "finite memory" in the formula for the calculation of the initial pension and appears to be fading after the 1997 legislation increased the number of years used in that calculation from eight to fifteen.

A crucial difference with respect to the general scheme is that, under the RETA, recipiency of an old age pension is compatible with maintaining the self-employed status. Other important provisions are the following: RETA only requires five years of contributions in the ten years immediately before the death of the principal in order to qualify for survivors pensions. Under RETA, the latter is 50 percent of the benefit base. If the principal was not a pensioner at the time of death, the benefit base is computed as the average of covered earnings over an uninterrupted period of five years chosen by the beneficiary among the last ten years before the death of the principal.

\section{Rules for Central Government Employees (RCP)}

We now describe briefly the main differences between the general scheme and the RCP, the pension fund for the employees of the central government. 
Public servants are divided into five categories, labeled from A to E, corresponding loosely to decreasing school levels: A for college graduates, B for people holding certain kinds of college diplomas, $\mathrm{C}$ for high school graduates, $\mathrm{D}$ for junior high school diplomas, and $\mathrm{E}$ for individuals with lower education levels. For each of these categories, the budget law defines every year a theoretical Social Security wage, which is used to compute Social Security contributions and pensions. The implied wage scale has remained relatively constant since 1985 . The top to bottom ratio never exceeded 2.5.

The basic monthly pension of a public servant who retires in month $t$ after contributing for $n$ years to RCP is computed as $P_{t}=\alpha_{n} \mathrm{BR}_{t}$, where the dependence of $\alpha_{n}$ upon the numbers of years worked has changed frequently over time. For $n \geq 15$, the last table of proportionality factors, legislated in 1990, can be reasonably (but not exactly) approximated by:

$$
\alpha_{n}=\min [1,1-0.0366(35-\mathrm{n})] .
$$

The differences with respect to the general scheme are various. First, while the entitlement to a pension still requires at least fifteen years of contributions, the replacement rate (the ratio of the pension to the benefit base) increases somewhat irregularly with seniority up to 100 percent after thirtyfive years. So, for example, fifteen years of service give right to a pension equal to only 26.92 percent of the benefit base, against 60 percent of the general scheme. After thirty years, the same ratio has increased to 81.73 percent, against 90 percent for the general scheme.

Second, the benefit base is computed as a weighted average of covered earnings upon which the worker paid the contributions, with weights equal to the percentage of the career spent at each level, that is,

$$
\mathrm{BR}_{t}=\sum_{i} p_{i} H_{i t}
$$

where $p_{i}$ is the fraction of the career spent on level $i$ and $H_{i t}$ are the covered earnings corresponding to level $i$, as determined by the current law at time $t$.

Third, unlike the general scheme, the RCP imposes mandatory retirement at age sixty-five. Exceptions are made for a few special categories, such as university professors and judges. On the other hand, the RCP allows for early retirement at the age of sixty, without any penalty for public servants with at least thirty years of service (twenty for military personnel).

A fourth important difference with respect to the general scheme is compatibility between RCP pension recipiency and income from continuing to work. In a number of special cases, RCP pensioners are allowed to keep a public-sector occupation, as long as this does not provide them with a "regular flow of income" (for example, this is the case of members of legislative bodies). More important, the legislation allows RCP pensions to be cumulated with earnings from employment in the private sector. 


\section{References}

Barrada, A. 1999. Public expenditure in social welfare in Spain from 1964 to 1995. Madrid: Fundación BBV.

Boldrin, M., J. Dolado, J. F. Jimeno, and F. Peracchi. 1999. The future of European pension systems. Economic Policy 29:289-320.

Boldrin, M., S. Jiménez-Martín, and F. Peracchi. 1999. Social security and retirement in Spain. In Social security programs and retirement around the world, ed. J. Gruber and D. Wise, 305-54. Chicago: University of Chicago Press.

. 2001. Pensions system and labor market in Spain. Madrid: Fundación BBVA.

- 2004. Micro-modeling of retirement behavior in Spain. In Social security and retirement around the world: Microestimations, ed. J. Gruber and D. Wise, 499-578. Chicago: University of Chicago Press.

Coile, C., and J. Gruber. 2000. Social security incentives for retirement. NBER Working Paper no. 7651. Cambridge, MA: National Bureau of Economic Research.

Gruber, J., and D. A. Wise. 1999. Social security programs and retirement around the world. Chicago: University of Chicago Press.

Instituto Nacional de Estadística (INE). 1995. Projections of the Spanish population. Madrid: INE.

Jiménez-Martín, S. 1999. Young's entry and older's exit from the labor force: What relationship, if any? Universidad Carlos III de Madrid. Unpublished Manuscript.

Kugler, A., J. F. Jimeno, and V. Hernanz. 2002. Employment consequences of restrictive permanent contracts: Evidence from Spanish labor market reforms. IZA Working Paper no. 657. Bonn, Germany: Institute for the Study of Labor.

Organization for Economic Cooperation and Development (OECD). 2005. OECD economic surveys: Spain. Paris: OECD.

Social Security, working histories continuous sample, since 2005. 2006. Available at: http://www.seg-social.es/Internet_1/Lanzadera/index.htm?URL=82.

Spanish Ministry of Labor and Social Affairs. 2005. Spanish strategy report regarding the future of the pension system. Madrid.

Stock, J. H., and D. A. Wise. 1990. Pensions, the option value of work, and retirement. Econometrica 58 (5): 1151-80. 